\title{
Adolescent idiopathic scoliosis: evidence for intrinsic factors driving aetiology and progression
}

\author{
Matthew M. P. Newton Ede ${ }^{1} \cdot$ Simon W. Jones $^{2}$ \\ Received: 18 January 2016 / Accepted: 8 February 2016/Published online: 10 March 2016 \\ (C) The Author(s) 2016. This article is published with open access at Springerlink.com
}

\begin{abstract}
Adolescent idiopathic scoliosis (AIS) is now considered to be a multifactorial heterogeneous disease, with recent genomic studies supporting the role of intrinsic factors in contributing to the onset of disease pathology and curve progression. Understanding the key molecular signalling pathways by which these intrinsic factors mediate AIS pathology may facilitate the development of pharmacological therapeutics and the identification of predictive markers of progression. The heterogenic nature of AIS has implicated multiple tissue types in the disease pathophysiology, including spinal bone, intervertebral disc and paraspinal muscles. In this review, we highlight some of the mechanisms and intrinsic molecular regulators within these different tissue types and review the evidence for their involvement in AIS pathology.
\end{abstract}

Keywords Adolescent idiopathic scolisosis · Epigenetics · Bone $\cdot$ Intervertebral disc $\cdot$ Paraspinal muscles

\section{Introduction}

Lateral curvature of the spine, for which there is no known cause, is the most common paediatric spinal deformity. In children aged between ten and 18 years, it is termed

Simon W. Jones

s.w.jones@bham.ac.uk

1 The Royal Orthopaedic Hospital NHS Foundation Trust, Bristol Road South, Northfield, Birmingham B31 2AP, UK

2 Institute of Inflammation and Ageing, MRC-ARUK Centre for Musculoskeletal Ageing Research, Medical School, Queen Elizabeth Hospital, University of Birmingham, B15 2WB Birmingham, UK adolescent idiopathic scoliosis (AIS) and affects between 2 and $3 \%$ of this population [42]. AIS is a highly heterogeneous condition, with some patients exhibiting rapidly progressive aggressive curves and others progressing more slowly with nonaggressive curves. AIS management includes bracing, growth modulation and fusion. However, these procedures are associated with significant morbidity $[42,49,68]$.

A number of theories have been proposed regarding the cause of AIS, including metabolic [1] and biomechanical [21] hypotheses, and several tissue types have been implicated in its pathogenesis, including bone, intervertebral discs and paravertebral muscles. The consensus is therefore that AIS is a multifactorial disease [12], with increasing evidence from genetic studies for the central role of intrinsic factors in contributing to its pathology and progression. Ultimately, clarifying the molecular basis for these pathogenic drivers will facilitate the development of pharmacological therapeutics. Furthermore, it will help to identify predictive markers of aggressive curves to inform clinicians and patients regarding the likely success or failure of nonfusion modalities (bracing or tethering). This review focuses on evidence for the involvement of spinal bone, intervertebral disc and paraspinal muscles tissues in the pathophysiology of AIS and reviews some potential key mechanisms and intrinsic molecular regulators within these tissues and cell types.

\section{Intrinsic factors of the AIS spinal musculoskeletal system}

\section{Spinal bone}

Importantly, there is now increasing evidence to support a role for abnormal spinal bone tissue as a primary intrinsic driver of AIS pathogenesis and a key determinant of curve progression 
$[12,15]$. It is has previously been reported that AIS patients exhibit lower lumbar spine bone mineral density (LSBMD) $[9,10,55]$ and altered vertebral growth $[9,10,29]$, resulting in disparity between the growth of anterior and posterior vertebrae, resulting in rotational lordosis. Furthermore, recent studies have reported osteopaenia as a prognostic indicator of curve progression [23, 57]. Significantly, several studies have provided evidence for the dysregulation of key molecular signalling pathways that are known regulators of bone mass and osteoblast cellular function. It is well established that central to the regulation of bone mass is osteoblast expression of receptor activator of nuclear factor kappa-B ligand (RANKL), which stimulates osteoclast activity and bone resorption by binding to RANK on the osteoclast membrane, and the osteoblast expression of osteoprotegerin (OPG), which acts as a decoy receptor for RANKL, thus inhibiting osteoclast activity and bone resorption [30]. Critically, genetic studies have shown associations between LSBMD with polymorphisms of OPG in girls diagnosed with AIS [16]. Furthermore, increased serum concentration of RANKL and an increase in the RANKL:OPG ratio, which would promote greater bone resorption, have been reported in patients with AIS, and were found to be negatively correlated to LSBMD [55].

Another line of evidence to support the hypothesis that intrinsic factors are central to AIS spinal bone pathology comes from studies on melatonin signalling. Melatonin is believed to promote bone mass by increasing the differentiation of mesenchymal stem cells (MSCs) into osteoblasts [54], promoting osteoblast proliferation [40] and reducing osteoblast RANKL expression [28]. In animal models of idiopathic scoliosis, such as the chick experimental pinealectomy model, the development of idiopathic scoliosis-like changes has been associated with reduced levels of serum melatonin. Furthermore, administration of melatonin has been shown to prevent the development of scoliosis in both chick and rodent models $[35,36]$. However, in humans, studies have predominantly reported no difference in serum melatonin levels in patients with or without AIS [5, 56], suggesting there would unlikely be any benefit to melatonin supplementation for patients with AIS. Critically, a more recent study has shown that melatonin can induce the proliferation of normal human osteoblasts but not osteoblasts from AIS female patients [37], suggesting an intrinsic dysfunction in melatonin signalling exists in human AIS spinal bone tissue. At present, the molecular basis for this intrinsic dysfunctional melatonin signalling is not fully understood. However, polymorphisms in melatonin receptor $1 \mathrm{~B}$ have been associated with the occurrence of idiopathic scoliosis [46, 47]. Furthermore, it has been demonstrated that melatonin stimulation of AIS osteoblasts results in differential phosphorylation of the $\mathrm{G}$ inhibitory signalling proteins that are coupled to the melatonin receptors, compared with normal osteoblasts [3].
Similarly, recent data suggests that the known association of the hormone estrogen with the onset and development of AIS may also be due to intrinsic differences in AIS spinal bone. Importantly, studies have found no significant difference in circulating estrogen levels between patients with AIS compared with control individuals [48], but polymorphisms in estrogen receptors have been found to be associated with AIS susceptibility and curve severity [45, 69], suggesting altered intrinsic estrogen signalling.

\section{Intervertebral disc and growth plate}

Patients with AIS exhibit "wedging" of the intervertebral disc, which is associated with a shift in the position of the nucleus pulposus to the convexity of the curve [31]. It is currently unclear whether these changes are a secondary response to spinal curvature and altered loading. However, changes to the intervertebral disc in AIS have been reported to occur early in the disease process, as detected by differences in magnetic resonance imaging (MRI) signal intensity [17]. In addition, MRI studies have detected central as well as concave and convex vertebral growth plate abnormalities to be frequently located near the apex of the curve [14], which could indicate that these abnormalities are a primary event.

The biological processes and molecular mechanisms that underlie these observed growth plate intervertebral disc abnormalities are poorly understood. However, histopathological studies have provided evidence for the disorganisation of columns of chondrocytes in the convex zone of the growth plate from a patient with AIS [14]. Furthermore, several studies have provided evidence for intervertebral disc matrix degeneration in AIS, with reduced proteoglycan content [50], decreased sulphation and acetylation of proteoglycans within the cartilaginous end plate and nucleus pulposus [52]. In addition, in the annulus fibrosus of AIS patients, vacuolation [41] and abnormal localisation of collagen fibres have been reported [7].

Importantly, histological analysis comparing anterior and posterior AIS growth plates have shown larger proliferative and hypertrophic chondrocyte zones in anterior compared with posterior samples [70]. Similarly, significantly greater proliferative and apoptotic chondrocytes have been reported in the convex side than in the concave side in the apex vertebral growth plate in AIS [62]. It is known from studies of joint cartilage degeneration that proliferative hypertrophic chondrocytes display a differential phenotype. For example, reduced expression of type II collagen, increased expression of cartilaginous and aggrecan proteoglycan proteases and increased expression of transcription factor Runx 2 and type 10 collagen [59], which ultimately facilitates cartilaginous matrix degeneration and endochondral ossification. Of relevance, therefore, is the finding that AIS convex and concave vertebral 
growth plates display differential expression of both Runx2 and type 10 collagen [61].

Given the evidence for dysfunctional melatonin signalling in AIS osteoblasts, it is of particular interest that a recent study has implicated the involvement of melatonin in AIS growth plate endochondral ossification abnormalities [63]. That study reported that growth plate chondrocytes from AIS patients exhibited reduced expression of the melatonin receptor MT2 compared with normal growth plate chondrocytes; furthermore, in response to melatonin stimulation, there was no inhibitory effect on their proliferative activity. Given that the normal chondrocyte response to melatonin was inhibition of proliferation [63], the absence of this antiproliferative response to melatonin in AIS chondrocytes may result in driving a proliferative hypertrophic chondrocyte with an abnormal phenotype, which promotes endochondral ossification.

It is debatable whether these changes are primary events in the development of AIS. Indeed, animal models of idiopathic scoliosis suggest these changes may be a result of uneven loading [66]. Regardless, it is certainly feasible that a loss of proteoglycan matrix within the intervertebral disc or a differential change in chondrocyte phenotype between concave and convex vertebral growth plates could result in disc deformation and contribute towards promoting curve progression. Therefore, identifying candidate drivers of these abnormal changes in AIS intervertebral discs is important.

One family of candidate mediators are proinflammatory cytokines such as interleukin (IL)-1 $\beta$, tumour necrosis factor (TNF)- $\alpha$ and IL-6, which are known drivers of cartilaginous matrix degeneration via the induction of matrix metalloproteases and aggrecanases [24]. Of potential significance, therefore, is a recent publication reporting a significant association between a functional polymorphism in IL-6 with susceptibility to idiopathic scoliosis and to curve severity [43]. Furthermore, there may be much to learn from studies that have examined the molecular basis for intervertebral disc degeneration in nonidiopathic scoliosis patient samples, where aberrant proliferation of cells in the nucleus pulposus is also implicated in the pathogenesis. Recent studies have reported that the noncoding micro-RNAs miR-10b and miR-21 can both promote nucleus pulposus cellular proliferation via inhibition of protein kinase $\mathrm{B}$ (AKT) signalling pathways $[32,67]$. Both miR-10b and miR-21 expression were reported to be higher in nucleus pulposus tissue from patients with identified intervertebral disc degeneration compared with nucleus pulposus tissue from patients with idiopathic scoliosis. Importantly, however, it is not known how the expression of these miRNAs compares between idiopathic scoliosis and normal nondegenerative nucleus pulposus tissue.

\section{Paraspinal muscles}

Paraspinal (paravertebral) muscles play a key role in controlling spinal stability [13]. Therefore, one theory is that dysfunctional paraspinal muscles may contribute towards development of the scoliotic curve. Electromyography (EMG) analysis of paraspinal muscles to assess muscle activation patterns in AIS patients have provided evidence of asymmetry [2] and abnormalities in neuromuscular transmission [58]. It is not possible to determine from these particular studies whether such observations are secondary events. However, more recent studies have suggested that EMG activity of paraspinal muscles is predictive for curve progression in AIS patients $[8,11]$.

Several studies have reported differences in the paraspinal muscles between convex and concave sides of the curve in patients with AIS. In vivo measurements of muscle protein synthesis rates using stable isotopes have demonstrated reduced levels of protein synthesis in the paraspinal muscles on the concave side of the spinal curve compared with the convex paraspinal muscles [18]. Histological studies have also shown that paraspinal muscles on the concave side of the scoliosis apex exhibit greater fibrosis and fatty involution [60] compared with muscles on the convex side.

Few studies have compared the phenotype of paraspinal muscles from AIS patients with age-matched control paraspinal muscle tissue. One such study, however, found AIS concave paraspinal muscle exhibited a difference in the proportion of muscle fibre types, with a significantly lower percentage of type I slow fibres found in AIS compared with control muscle [38]. This finding suggests that a switch in the phenotype of AIS paraspinal muscle occurs, with a shift towards a faster, more glycolytic muscle phenotype, with reduced fatigue resistance. Of note, this particular study found no difference in fibre type between AIS and control muscles on the convex side, supporting the notion that it is the muscles on the concave side of the curve that are most affected in AIS [38].

These differential findings in paraspinal muscle pathology between concave and convex sides of the scoliosis apex could indicate that the muscle dysfunction is simply a secondary event due to postural changes upon spinal curvature. However, recent genetic studies have provided preliminary evidence that skeletal muscle dysfunction could be a contributory factor in AIS susceptibility: Firstly, rare variants in fibrillin-1 (FBN1) and fibrillin-2 (FBN2) have been found to be associated with severe AIS [6]. FBN1 and 2 are glycoproteins that form key components of skeletal muscle myofibrillar structure. Deficiency in FBN1 is associated with the connective tissue disorder Marfan's syndrome, a condition characterised by poor muscle development and muscle myopathy [4]. Indeed, $60 \%$ of patients with Marfan's syndrome develop scoliosis. Interestingly, the recent publication by Wajchenberg et al. [60] reported signs of muscle myopathy and muscular atrophy in the paraspinal muscles on both the concave and convex sides of the scoliosis apex.

Similarly, a recent genome-wide association study identified the ladybird homeobox 1 ( $L B X 1)$ locus as being associated with AIS susceptibility in both Asian and non-Hispanic 
white populations [34]. From animal models, $L B X 1$ has been shown to play a critical role in muscular development. In addition, functional polymorphisms in the transforming growth factor beta $(T G F-\beta)$ gene have been found to be associated with AIS susceptibility and in females to be associated with curve severity [53]. Abnormalities in TGF- $\beta$ signalling are associated with several musculoskeletal disorders, including Duchenne muscular dystrophy [51], and it is a known inducer of muscle atrophy through induction in expression of muscle-specific ligase Atrogin-1 [19]. It is notable, therefore, that a recent study reported differential expression of TGF- $\beta$ and TGF- $\beta$ receptors with upregulation of TGF- $\beta$ responsive genes in paravertebral muscles from the concave side of the curve apex compared with the convex side [44]. This data is indicative of abnormal TGF- $\beta$ signalling in the paravertebral muscles of patients with AIS and could therefore be a contributory factor to the abnormal paraspinal muscle pathology observed in AIS patients.

\section{Epigenetics}

It was initially envisaged that upon completion of the human genome project our understanding of human disease would lead to an abundance in the development of new targeted therapies by which to modify disease progression or prevent disease onset [25]. However, in recent years, it has become increasingly apparent that many diseases are likely to be the result of the interaction between intrinsic genes and the external environment [22], which can result in modification to gene transcription and thus impact biological processes. This understanding has led to the emergence of the research field known as epigenetics, which includes analysis of DNA methylation, histone modifications and transcription of noncoding RNAs [20,27] such as miRNAs and long noncoding RNAs (lncRNAs). Such approaches may lead not only to an improved understanding of AIS but also help identify at-risk individuals and predict aggressive curves. Evidence that AIS may be a result of epigenetics is supported by reports of differences in spinal radiology in monozygotic twins with AIS [26] and from the increased incidence of AIS in relation to nutrition [64], physical activity [39] and maternal age [65]. Of importance, therefore, a recent study that performed microarray analysis and identified 139 lncRNAs (epigenetic regulators of gene transcription) that were differentially expressed in the peripheral blood of patients with AIS compared with control individuals [33]. As yet, however, no studies have performed RNA sequencing of AIS and control spinal human tissues to ascertain the full transcriptomic epigenetic profile of diseased AIS spinal tissue in humans. Furthermore, there are no reports of DNA methylation analysis of AIS patient tissues.

\section{Summary}

Despite AIS being the most common paediatric spinal deformity, very little is understood about the molecular basis of the disease pathology. However, current consensus is that AIS is likely to be a multifactorial condition involving both extrinsic and intrinsic factors, suggesting that epigenetic differences may underlie the disease pathology. To this end, it will be important to conduct epigenetic studies including full RNA transcriptomic sequencing and DNA methylation of spinal tissues (spinal bone, intervertebral disc, paravertebral muscles) in which AIS tissues are compared with age- and gender-matched normal control tissues. Ultimately, identifying the key intrinsic factors localised to the spinal tissues, and understanding their relationship to extrinsic factors and disease phenotype, may lead to the development of personalised disease-modifying therapeutics and also to biomarkers that can predict patient outcome, thus guiding clinical decision making.

\section{Compliance with ethical standards}

Conflict of interest None

Open Access This article is distributed under the terms of the Creative Commons Attribution 4.0 International License (http:// creativecommons.org/licenses/by/4.0/), which permits unrestricted use, distribution, and reproduction in any medium, provided you give appropriate credit to the original author(s) and the source, provide a link to the Creative Commons license, and indicate if changes were made.

\section{References}

1. Acaroglu E, Bobe R, Enouf J, Marcucio R, Moldovan F, Moreau A (2012) The metabolic basis of adolescent idiopathic scoliosis: 2011 report of the "metabolic" workgroup of the Fondation Yves Cotrel. Eur Spine J 21:1033-1042

2. Avikainen VJ, Rezasoltani A, Kauhanen HA (1999) Asymmetry of paraspinal EMG-time characteristics in idiopathic scoliosis. J Spinal Disord 12:61-67

3. Azeddine B, Letellier K, Wang DS, Moldovan F, Moreau A (2007) Molecular determinants of melatonin signaling dysfunction in adolescent idiopathic scoliosis. Clin Orthop Relat Res 462:45-52

4. Behan WM, Longman C, Petty RK, Comeglio P, Child AH, Boxer M, Foskett P, Harriman DG (2003) Muscle fibrillin deficiency in Marfan's syndrome myopathy. J Neurol Neurosurg Psychiatry 74: 633-638

5. Brodner W, Krepler P, Nicolakis M, Langer M, Kaider A, Lack W, Waldhauser F (2000) Melatonin and adolescent idiopathic scoliosis. J Bone Joint Surg Br 82:399-403

6. Buchan JG, Alvarado DM, Haller GE, Cruchaga C, Harms MB, Zhang T, Willing MC, Grange DK, Braverman AC, Miller NH, Morcuende JA, Tang NL, Lam TP, Ng BK, Cheng JC, Dobbs MB, Gurnett CA (2014) Rare variants in FBN1 and FBN2 are associated with severe adolescent idiopathic scoliosis. Hum Mol Genet 23:5271-5282 
7. Bushell GR, Ghosh P, Taylor TK (1978) Collagen defect in idiopathic scoliosis. Lancet 2:94-95

8. Busscher I, Wapstra FH, Veldhuizen AG (2010) Predicting growth and curve progression in the individual patient with adolescent idiopathic scoliosis: design of a prospective longitudinal cohort study. BMC Musculoskelet Disord 11:93

9. Cheng JC, Qin L, Cheung CS, Sher AH, Lee KM, Ng SW, Guo X (2000) Generalized low areal and volumetric bone mineral density in adolescent idiopathic scoliosis. J Bone Miner Res 15:1587-1595

10. Cheng JC, Tang SP, Guo X, Chan CW, Qin L (2001) Osteopenia in adolescent idiopathic scoliosis: a histomorphometric study. Spine (Phila Pa 1976) 26:E19-E23

11. Cheung J, Veldhuizen AG, Halbertsma JP, Maurits NM, Sluiter WJ, Cool JC, Van Horn JR (2004) The relation between electromyography and growth velocity of the spine in the evaluation of curve progression in idiopathic scoliosis. Spine (Phila Pa 1976) 29:10111016

12. Cheung KM, Wang T, Qiu GX, Luk KD (2008) Recent advances in the aetiology of adolescent idiopathic scoliosis. Int Orthop 32:729734

13. Cholewicki J, Panjabi MM, Khachatryan A (1997) Stabilizing function of trunk flexor-extensor muscles around a neutral spine posture. Spine (Phila Pa 1976) 22:2207-2212

14. Day G, Frawley K, Phillips G, McPhee IB, LaBrom R, Askin G, Mueller P (2008) The vertebral body growth plate in scoliosis: a primary disturbance of growth? Scoliosis 3:3

15. Dickson RA (1988) The aetiology of spinal deformities. Lancet 1: 1151-1155

16. Eun IS, Park WW, Suh KT, Kim JI, Lee JS (2009) Association between osteoprotegerin gene polymorphism and bone mineral density in patients with adolescent idiopathic scoliosis. Eur Spine J 18:1936-1940

17. Gervais J, Perie D, Parent S, Labelle H, Aubin CE (2012) MRI signal distribution within the intervertebral disc as a biomarker of adolescent idiopathic scoliosis and spondylolisthesis. BMC Musculoskelet Disord 13:239

18. Gibson JN, McMaster MJ, Scrimgeour CM, Stoward PJ, Rennie MJ (1988) Rates of muscle protein synthesis in paraspinal muscles: lateral disparity in children with idiopathic scoliosis. Clin Sci (Lond) 75:79-83

19. Gumucio JP, Mendias CL (2013) Atrogin-1, MuRF-1, and sarcopenia. Endocrine 43:12-21

20. Guttman M, Amit I, Garber M, French C, Lin MF, Feldser D, Huarte M, Zuk O, Carey BW, Cassady JP, Cabili MN, Jaenisch R, Mikkelsen TS, Jacks T, Hacohen N, Bernstein BE, Kellis M, Regev A, Rinn JL, Lander ES (2009) Chromatin signature reveals over a thousand highly conserved large noncoding RNAs in mammals. Nature 458:223-227

21. Hefti F (2013) Pathogenesis and biomechanics of adolescent idiopathic scoliosis (AIS). J Child Orthop 7:17-24

22. Heindel JJ, Balbus J, Birnbaum L, Brune-Drisse MN, Grandjean P, Gray K, Landrigan PJ, Sly PD, Suk W, Cory SD, Thompson C, Hanson M (2015) Developmental origins of health and disease: integrating environmental influences. Endocrinology 156:34163421

23. Hung VW, Qin L, Cheung CS, Lam TP, Ng BK, Tse YK, Guo X, Lee KM, Cheng JC (2005) Osteopenia: a new prognostic factor of curve progression in adolescent idiopathic scoliosis. J Bone Joint Surg Am 87:2709-2716

24. Jones SW, Brockbank SM, Clements KM, Le GN, Campbell D, Read SJ, Needham MR, Newham P (2009) Mitogen-activated protein kinase-activated protein kinase 2 (MK2) modulates key biological pathways associated with OA disease pathology. Osteoarthritis Cartilage 17:124-131

25. Jones SW, Lindsay MA (2004) Overview of target validation and the impact of oligonucleotides. Curr Opin Mol Ther 6:546-550
26. Kesling KL, Reinker KA (1997) Scoliosis in twins. A meta-analysis of the literature and report of six cases. Spine (Phila Pa 1976) 22: 2009-2014

27. Khalil AM, Guttman M, Huarte M, Garber M, Raj A, Rivea MD, Thomas K, Presser A, Bernstein BE, Van OA, Regev A, Lander ES, Rinn JL (2009) Many human large intergenic noncoding RNAs associate with chromatin-modifying complexes and affect gene expression. Proc Natl Acad Sci U S A 106:11667-11672

28. Koyama H, Nakade O, Takada Y, Kaku T, Lau KH (2002) Melatonin at pharmacologic doses increases bone mass by suppressing resorption through down-regulation of the RANKLmediated osteoclast formation and activation. J Bone Miner Res 17:1219-1229

29. Lam TP, Hung VW, Yeung HY, Tse YK, Chu WC, Ng BK, Lee KM, Qin L, Cheng JC (2011) Abnormal bone quality in adolescent idiopathic scoliosis: a case-control study on 635 subjects and 269 normal controls with bone densitometry and quantitative ultrasound. Spine (Phila Pa 1976) 36:1211-1217

30. Lemaire V, Tobin FL, Greller LD, Cho CR, Suva LJ (2004) Modeling the interactions between osteoblast and osteoclast activities in bone remodeling. J Theor Biol 229:293-309

31. Little JP, Pearcy MJ, Izatt MT, Boom K, Labrom RD, Askin GN, Adam CJ (2015) Understanding how axial loads on the spine influence segmental biomechanics for idiopathic scoliosis patients: A magnetic resonance imaging study. Clin Biomech (Bristol, Avon) 32:220-8

32. Liu H, Huang X, Liu X, Xiao S, Zhang Y, Xiang T, Shen X, Wang G, Sheng B (2014) miR-21 promotes human nucleus pulposus cell proliferation through PTEN/AKT signaling. Int J Mol Sci 15:40074018

33. Liu XY, Wang L, Yu B, Zhuang QY, Wang YP (2015) Expression signatures of long noncoding RNAs in adolescent idiopathic scoliosis. Biomed Res Int 2015:276049. doi:10.1155/2015/276049

34. Londono D, Kou I, Johnson TA, Sharma S, Ogura Y, Tsunoda T, Takahashi A, Matsumoto M, Herring JA, Lam TP, Wang X, Tam EM, Song YQ, Fan YH, Chan D, Cheah KS, Qiu X, Jiang H, Huang D, TSRHC IS Clinical Group, International Consortium for Scoliosis Genetics, Su P, Sham P, Cheung KM, Luk KD, Gordon D, Qiu Y, Cheng J, Tang N, Ikegawa S, Wise CA (2014) A meta-analysis identifies adolescent idiopathic scoliosis association with LBX1 locus in multiple ethnic groups. J Med Genet 51: 401-406

35. Machida M, Dubousset J, Satoh T, Murai I, Wood KB, Yamada T, Ryu J (2001) Pathologic mechanism of experimental scoliosis in pinealectomized chickens. Spine (Phila Pa 1976) 26:E385-E391

36. Machida M, Murai I, Miyashita Y, Dubousset J, Yamada T, Kimura J (1999) Pathogenesis of idiopathic scoliosis. Experimental study in rats. Spine (Phila Pa 1976) 24:1985-1989

37. Man GC, Wang WW, Yeung BH, Lee SK, Ng BK, Hung WY, Wong JH, Ng TB, Qiu Y, Cheng JC (2010) Abnormal proliferation and differentiation of osteoblasts from girls with adolescent idiopathic scoliosis to melatonin. J Pineal Res 49:69-77

38. Mannion AF, Meier M, Grob D, Muntener M (1998) Paraspinal muscle fibre type alterations associated with scoliosis: an old problem revisited with new evidence. Eur Spine J 7:289-293

39. McMaster ME, Lee AJ, Burwell RG (2015) Physical activities of Patients with adolescent idiopathic scoliosis (AIS): preliminary longitudinal case-control study historical evaluation of possible risk factors. Scoliosis 10:6

40. Nakade O, Koyama H, Ariji H, Yajima A, Kaku T (1999) Melatonin stimulates proliferation and type I collagen synthesis in human bone cells in vitro. J Pineal Res 27:106-110

41. Nakamura T (1980) Histopathological study on the intervertebral discs of idiopathic scoliosis (author's transl). Nihon Seikeigeka Gakkai Zasshi 54:523-538 
42. Negrini S, De Mauroy JC, Grivas TB, Knott P, Kotwicki T, Maruyama T, O’Brien JP, Rigo M, Zaina F (2014) Actual evidence in the medical approach to adolescents with idiopathic scoliosis. Eur J Phys Rehabil Med 50:87-92

43. Nikolova S, Dikova M, Dikov D, Djerov A, Dzhebir G, Atanasov V, Savov A, Kremensky I (2015) Role of the IL-6 gene in the etiopathogenesis of idiopathic scoliosis. Anal Cell Pathol (Amst) 2015:621893. doi:10.1155/2015/621893

44. Nowak R, Kwiecien M, Tkacz M, Mazurek U (2014) Transforming growth factor-beta (TGF- beta) signaling in paravertebral muscles in juvenile and adolescent idiopathic scoliosis. Biomed Res Int 2014:594287. doi: $10.1155 / 2014 / 594287$

45. Peng Y, Liang G, Pei Y, Ye W, Liang A, Su P (2012) Genomic polymorphisms of G-protein estrogen receptor 1 are associated with severity of adolescent idiopathic scoliosis. Int Orthop 36:671-677

46. Qiu XS, Tang NL, Yeung HY, Lee KM, Hung VW, Ng BK, Ma SL, Kwok RH, Qin L, Qiu Y, Cheng JC (2007) Melatonin receptor 1B (MTNR1B) gene polymorphism is associated with the occurrence of adolescent idiopathic scoliosis. Spine (Phila Pa 1976) 32:1748-1753

47. Qiu XS, Tang NL, Yeung HY, Qiu Y, Qin L, Lee KM, Cheng JC (2006) The role of melatonin receptor 1B gene (MTNR1B) in adolescent idiopathic scoliosis-A genetic association study. Stud Health Technol Inform 123:3-8

48. Raczkowski JW (2007) The concentrations of testosterone and estradiol in girls with adolescent idiopathic scoliosis. Neuro Endocrinol Lett 28:302-304

49. Rainoldi L, Zaina F, Villafane JH, Donzelli S, Negrini S (2015) Quality of life in normal and idiopathic scoliosis adolescents before diagnosis: reference values and discriminative validity of the SRS22. A cross-sectional study of 1,205 pupils. Spine J 15:662-667

50. Roberts S, Menage J, Eisenstein SM (1993) The cartilage end-plate and intervertebral disc in scoliosis: calcification and other sequelae. J Orthop Res 11:747-757

51. Ruegg UT (2013) Pharmacological prospects in the treatment of Duchenne muscular dystrophy. Curr Opin Neurol 26:577-584

52. Rusova TV, Rykova VI, Korel AV, Zaidman AM, Tkachev DS (2005) Glycosaminoglycans of the vertebral body growth plate in patients with idiopathic scoliosis. Bull Exp Biol Med 139:738-740

53. Ryzhkov II, Borzilov EE, Churnosov MI, Ataman AV, Dedkov AA, Polonikov AV (2013) Transforming growth factor beta 1 is a novel susceptibility gene for adolescent idiopathic scoliosis. Spine (Phila Pa 1976) 38:E699-E704

54. Satomura K, Tobiume S, Tokuyama R, Yamasaki Y, Kudoh K, Maeda E, Nagayama M (2007) Melatonin at pharmacological doses enhances human osteoblastic differentiation in vitro and promotes mouse cortical bone formation in vivo. J Pineal Res 42:231-239

55. Suh KT, Lee SS, Hwang SH, Kim SJ, Lee JS (2007) Elevated soluble receptor activator of nuclear factor-kappaB ligand and reduced bone mineral density in patients with adolescent idiopathic scoliosis. Eur Spine J 16:1563-1569

56. Suh KT, Lee SS, Kim SJ, Kim YK, Lee JS (2007) Pineal gland metabolism in patients with adolescent idiopathic scoliosis. J Bone Joint Surg Br 89:66-71
57. Sun X, Wu T, Liu Z, Zhu Z, Qian B, Zhu F, Ma W, Yu Y, Wang B, Qiu Y (2013) Osteopenia predicts curve progression of adolescent idiopathic scoliosis in girls treated with brace treatment. J Pediatr Orthop 33:366-371

58. Trontelj JV, Fernandez JM (1988) Single fiber EMG in juvenile idiopathic scoliosis. Muscle Nerve 11:297-300

59. van der Kraan PM, van den Berg WB (2012) Chondrocyte hypertrophy and osteoarthritis: role in initiation and progression of cartilage degeneration? Osteoarthritis Cartilage 20: 223-232

60. Wajchenberg M, Martins DE, Luciano RP, Puertas EB, Del CD, Schmidt B, Oliveira AB, Faloppa F (2015) Histochemical analysis of paraspinal rotator muscles from patients with adolescent idiopathic scoliosis: a cross-sectional study. Medicine (Baltimore) 94: e598

61. Wang S, Qiu Y, Ma Z, Xia C, Zhu F, Zhu Z (2010) Expression of Runx2 and type $X$ collagen in vertebral growth plate of patients with adolescent idiopathic scoliosis. Connect Tissue Res 51:188 196

62. Wang S, Qiu Y, Zhu Z, Ma Z, Xia C, Zhu F (2007) Histomorphological study of the spinal growth plates from the convex side and the concave side in adolescent idiopathic scoliosis. J Orthop Surg Res 2:19

63. Wang WW, Man GC, Wong JH, Ng TB, Lee KM, Ng BK, Yeung HY, Qiu Y, Cheng JC (2014) Abnormal response of the proliferation and differentiation of growth plate chondrocytes to melatonin in adolescent idiopathic scoliosis. Int J Mol Sci 15:17100-17114

64. Worthington V, Shambaugh P (1993) Nutrition as an environmental factor in the etiology of idiopathic scoliosis. J Manipulative Physiol Ther 16:169-173

65. Wynne-Davies R (1968) Familial (idiopathic) scoliosis. A family survey. J Bone Joint Surg Br 50:24-30

66. Yoshihara H, Kawakami N, Matsuyama Y, Inoh H, Imagama S, Ishiguro N (2005) A histomorphologic study of scoliosis in pinealectomized chickens. Spine (Phila Pa 1976) 30:2244 2251

67. Yu X, Li Z, Shen J, Wu WK, Liang J, Weng X, Qiu G (2013) MicroRNA-10b promotes nucleus pulposus cell proliferation through RhoC-Akt pathway by targeting HOXD10 in intervetebral disc degeneration. PLoS One 8:e83080

68. Zaina F, De Mauroy JC, Grivas T, Hresko MT, Kotwizki T, Maruyama T, Price N, Rigo M, Stikeleather L, Wynne J, Negrini S (2014) Bracing for scoliosis in 2014: state of the art. Eur J Phys Rehabil Med 50:93-110

69. Zhang HQ, Lu SJ, Tang MX, Chen LQ, Liu SH, Guo CF, Wang XY, Chen J, Xie L (2009) Association of estrogen receptor beta gene polymorphisms with susceptibility to adolescent idiopathic scoliosis. Spine (Phila Pa 1976) 34:760-764

70. Zhu F, Qiu Y, Yeung HY, Lee KM, Cheng JC (2006) Histomorphometric study of the spinal growth plates in idiopathic scoliosis and congenital scoliosis. Pediatr Int 48:591-598 